\title{
Relationship of chronological age and sexual maturity with skeletal maturity by magnetic resonance imaging of the distal radial epiphysis in adolescent football players
}

\author{
Jesús Bolívar ${ }^{\mathrm{a}, \mathrm{b}}$, Óscar Sandoval ${ }^{\mathrm{c}}$, Jorge Osorio ${ }^{\mathrm{a}, \mathrm{b}}$, Gabriel Dib $^{\mathrm{d}}$, Jaime Gallo ${ }^{\mathrm{a}, \mathrm{b}, \mathrm{e}, *}$ \\ a Faculty of Medicine, University of Antioquia, Medellin, Colombia \\ ${ }^{\mathrm{b}}$ Research Group in Medicine Applied to Physical Activity and Sport - GRINMADE, University of Antioquia, Medellín, Colombia \\ c University Hospital of Neiva, Neiva, Colombia \\ d Advanced Centre of Diagnostic Medicine (CEDIMED), Medellín, Colombia \\ e Clinical and Research Centre (SICOR), Medellín, Colombia
}

Received 3 February 2015; accepted 25 May 2015

Available online 29 June 2015

\section{KEYWORDS}

Age determination by skeleton;

Sexual development; Adolescent; Magnetic resonance imaging;

Epiphysis;

Football

\begin{abstract}
Introduction: Although the grade of fusion of the left distal radial epiphysis (LDRE) observed by magnetic resonance imaging (MRI) has been linked to chronological age (CA), its relationship to Tanner stage of the genitals in the Latin American population is unknown.

Objective: To evaluate the relationship of CA and sexual maturity with skeletal maturity (SM) determined by MRI of the LDRE in adolescent football players from Medellin, Colombia.

Materials and methods: Cross-sectional study that included 60 male football players with certified legal age between 12 and 18 years. Medical evaluation and MRI of the LDRE using a 1.5T scanner was performed according to a described protocol. The image reading was performed by 3 blinded evaluators. SM was classified as: A: immature; B: developing; C: mature, and interand intra-observer variability was assessed.

Results: Among the football players included in the study, the average body mass index and body fat were $19.6 \pm 2.0 \mathrm{~kg} / \mathrm{m}^{2}$ and $11.1 \pm 1.2 \%$, respectively. A correlation of CA and the Tanner stage of genital maturity with SM (Kendall's Tau_b 0.686 and 0.693 , respectively; $P<.001$ ) was found. All players classified as stage $C$ were 17 or older and Tanner stage $V$. The inter-observer and intraobserver agreement showed a kappa index of $0.36(P<.001)$ and $0.60(P<.001)$, respectively.
\end{abstract}

\footnotetext{
* Corresponding author.

E-mail address: jagallo2000@yahoo.com (J. Gallo).
} 
Conclusion: A relationship was found between CA and sexual maturity and SM by MRI of the LDRE in adolescent football players. Classification by stage of SM in 3 categories could be more practical and have implications for competition.

(C) 2015 Consell Català de l'Esport. Generalitat de Catalunya. Published by Elsevier España, S.L.U. All rights reserved.

\section{PALABRAS CLAVE}

Determinación de la edad por el esqueleto; Desarrollo sexual; Adolescente; Imagen por resonancia magnética; Epífisis;

Fútbol
Relación de la edad cronológica y la maduración sexual con la maduración ósea por resonancia magnética nuclear de la epífisis del radio distal en futbolistas adolescentes

\section{Resumen}

Introducción: Aunque el grado de fusión de la epífisis del radio distal izquierdo (ERDI) por resonancia magnética nuclear (RMN) se ha relacionado con la edad cronológica (EC), se desconoce su relación con el Tanner genital en población latinoamericana.

Objetivo: Evaluar la relación de la EC y la maduración sexual con la maduración ósea $(\mathrm{MO})$ por RMN de la ERDI en futbolistas adolescentes de la ciudad de Medellín, Colombia.

Materiales y métodos: Estudio transversal que incluyó 60 futbolistas hombres con edad legal certificada entre 12 y 18 años. Se realizó una evaluación médica y una RMN de la ERDI con un resonador de $1.5 \mathrm{~T}$ según un protocolo descrito. La lectura de la imagen fue realizada por 3 evaluadores cegados. Se determinó la MO en tres estadios (A: inmaduros; B: en desarrollo; C: maduros) y se evaluó la variabilidad inter e intra-observador.

Resultados: Entre los futbolistas incluidos, se encontró un promedio de índice de masa corporal y porcentaje de grasa corporal de $19,6 \pm 2,0 \mathrm{Kg} / \mathrm{m}^{2}$ y $1,1 \pm 1,2 \%$, respectivamente. Se encontró correlación de la EC y el estadio de maduración por Tanner genital con la MO (Tau_b de Kendall 0,686 y 0,693 , respectivamente; $p<0,001$ ). Todos los jugadores clasificados en el grado $C$ tenían 17 o más años y Tanner estadio V. La concordancia inter-observador e intra-observador, mostró un índice kappa de 0,36 ( $p<0,001)$ y 0,60 $(p<0,001)$, respectivamente.

Conclusión: Se encontró relación de la EC y la maduración sexual con la MO por RMN de la ERDI en futbolistas adolescentes. La clasificación por grados de $M O$ en 3 categorías, podría ser más práctica y tener implicaciones para la competencia.

(C) 2015 Consell Català de l'Esport. Generalitat de Catalunya. Publicado por Elsevier España, S.L.U. Todos los derechos reservados.

\section{Introduction}

In the lower divisions of Colombian and international football leagues, misconduct has been described that falsifies and/or supplants identity documents to integrate older individuals into sports participation by claiming a younger age. Some of these players are perceived as talented players, when in reality, they are more mature individuals than appropriate for the divisions. . $^{1,2}$

The available methods for determining bone age based on X-ray studies are imprecise and not validated in our population $^{3}$; currently, screening procedures using X-rays are inadequate, and research studies are prohibited from using this type of technique. ${ }^{4}$

Studies conducted at the Centre for Medical Research and Assessment of the International Federation of Association Football (FIFA, for its initials in French) show that Magnetic Resonance Imaging (MRI) of the left distal radial epiphysis (LDRE) can be used to determine the grade of skeletal maturity (SM) more dependably than X-ray techniques. ${ }^{5}$ In the validation study of the method, a classification scheme of 6 progressive grades was described $(I-V I)$, according to the fusion of the LDRE in male football players between 14 and 19 years old in four different areas of the world (Switzerland, Algeria, Malaysia and Argentina). ${ }^{5}$ In this study involving 496 players, it was found that between 16 and 17 year olds, less than $1 \%$ had complete fusion, and at 19 years, $100 \%$ were completely fused. It was concluded that this method of evaluating the grade of SM by MRI of the LDRE is accurate, reliable, and reproducible. It also offers a non-invasive alternative for assessing the SM of players.

In addition, the same FIFA research group reported results from evaluating SM of the LDRE by MRI in 189 participating players in 4 international Sub-17 competitions (FIFA 2003 World Cup Sub-17 Finland, FIFA 2005 World Cup Sub-17 Peru, Asian Football Confederation AFC Sub-17 2004 Japan, AFC Sub-17 2006 Singapore). In this study, there was a lack of correlation between reported age and grade of fusion, which suggested that the players of these competitions were more mature than the reference population and reinforced suspicion that the age declared in official documents was not correct in all cases. ${ }^{6}$

The average age according to the grade of fusion of the LDRE by MRI can vary in different regions. ${ }^{5}$ The Colombian 
population, due to demographic, nutritional, and social aspects, may exhibit differences in bone fusion compared to other Latin American and world populations.

Although the grade of sexual maturity (Tanner stage) has been correlated with chronological age (CA), various studies have shown that maturity of the hypothalamic-pituitary-gonad axis, CA and SM according to X-rays are asynchronous in healthy young subjects. ${ }^{7,8}$ No studies that relate Tanner stage and grade of SM determined by MRI have been reported.

The aim of this study was to evaluate the relationship of CA and sexual maturity with SM determined by MRI of the LDRE in adolescent football players from the city of Medellin, Colombia.

\section{Methods}

A cross-sectional study that included male football players belonging to clubs participating in tournaments regulated by the Antioquia Football League in Colombia was conducted. All subjects were born from 1st January 1992 to 31 December 1997, so they were between 12 and 18 years by the time of the inclusion in the study.

\section{Subjects}

Adolescent football players were included, with age certified by a direct copy of the birth certificate folio, with civil registration date of birth up to a maximum of 3 months after the birth date. Once the documentation and information corroborated by experts of the Colombian National Registry were evaluated, the players were invited by telephone or by their coaches to participate in the selection process.

All participants and their legal custodians were informed of the purpose of the research and signed the informed consent forms authorised by the Bioethics Committee of the Medical Research Institute of the School of Medicine of the University of Antioquia.

After the players and guardians accepted participation in the study, a medical evaluation including medical history information and a complete physical examination was performed. The socioeconomic strata were defined according to official division in Colombian which include six categories (level one is lower-low and six is high). Anthropometric measurements, quantification of blood pressure, heart rate, heart-lung auscultation, and assessment of sexual maturity stage were performed. Weight was measured with a $\mathrm{KH}-2003 \mathrm{~B}$ scale to the nearest $0.1 \mathrm{~kg}$, height with a wall mounted stadiometer to the nearest $0.1 \mathrm{~cm}$ (SECA 208, Seca Ltd., Hamburg, Germany), and body mass index was calculated using the equation weight/height. ${ }^{2}$ To estimate percent body fat, the Yuhasz equation modified by Faulkner was used (\%fat = sum of four skinfolds (triceps, subscapular, suprailiac, abdominal) $\times 0.158+5.783) .{ }^{9}$ Skinfolds were measured using a Slimguide brand adipometer (Creative Health Products, Plymouth MI), and the stage of maturity of sexual characteristics was defined according to the Tanner scale. ${ }^{10}$

Individuals with a history of chronic diseases (diabetes, endocrine disorders, asthma, arthritis, heart disease), steroid use, fractures of the forearm or left carpus, or
Table 1 Classification criteria for six and three categories of ossification/fusion of the distal left radius epiphysis by nuclear magnetic resonance.

\begin{tabular}{lll}
\hline $\begin{array}{l}\text { Six } \\
\text { categories }\end{array}$ & $\begin{array}{l}\text { Three } \\
\text { categories }\end{array}$ & Definition \\
\hline II & A & $\begin{array}{l}\text { Completely unfused } \\
\text { Early fusion: showing minimal } \\
\text { hyperintensity within the } \\
\text { physis } \\
\text { Trabecular fusion of }<50 \% \text { of } \\
\text { the radial cross-sectional area } \\
\text { Trabecular fusion of }>50 \% \text { of } \\
\text { III }\end{array}$ \\
IV & B & $\begin{array}{l}\text { Residual physis, } 5 \text { mm on any } \\
\text { one section } \\
\text { Complete fusion of distal left } \\
\text { radius }\end{array}$ \\
V & C & \\
\hline
\end{tabular}

contraindications for MRI of the LDRE (presence of pacemakers, cochlear implants, metal clips in the central nervous system, or heart valves with ferromagnetic components) were excluded. Once the athlete met all the criteria for participating in the study, he was randomly assigned a threedigit code.

\section{Magnetic resonance imaging of the left distal radial epiphysis}

MRI of the LDRE was performed at a specialised diagnostic imaging centre in Medellin, Colombia. To obtain the image, standardisation parameters and the protocol described in research conducted at the FIFA Medical Research Centre were employed. ${ }^{5,6}$ A Siemens 1.5T MRI scanner was used; the wrist was placed overhead or alongside the body with the palm facing anteriorly in the coronal plane. Images were stored in digital format (picture archiving and communication system - PACS) and were taken under the same protocols; only the diagnostic centre technical staff had access to the codes identifying the participants.

\section{Image reading}

For image reading, the recommendations described in previous research were followed. 5,6 The readers, two radiologists and a sports medicine physician, were blinded as to the basic information on the participants. The results were given in a pre-set format and in a closed envelope, which only included a description of the assigned code, grade of fusion, and signature. Each image was read independently and at different times for each evaluator. Grade of fusion was the most common classification between the three results of the evaluators (Table 1) (Fig. 1).

According to observations made by investigators and considering results from previous studies, ${ }^{11} \mathrm{SM}$ in football can be divided into grades or stages to give homogeneity to the competition and avoid difficulties of CA. From the classification into six categories of the grade of fusion of the LDRE by MRI proposed in previous studies, ${ }^{5,6}$ a simple re-stratification was proposed in three categories according 

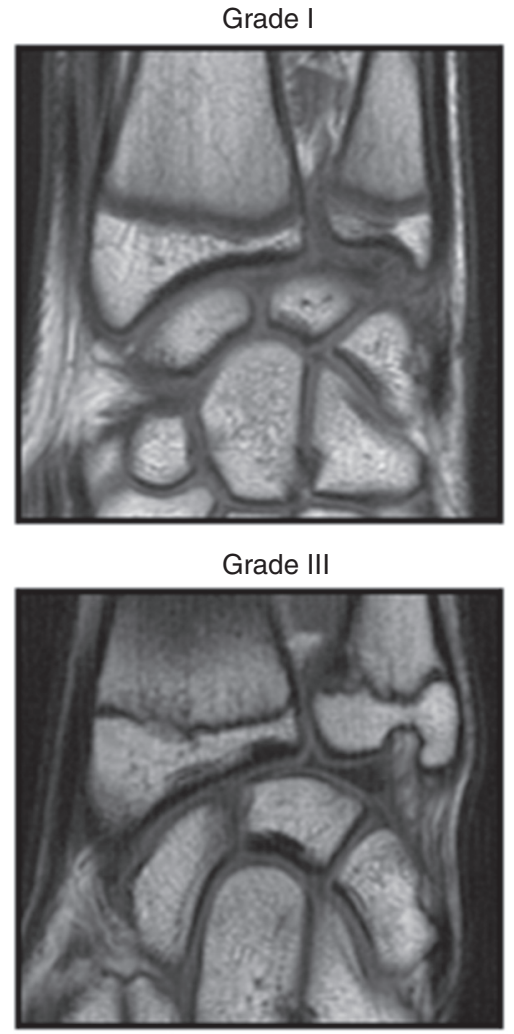

Grade V

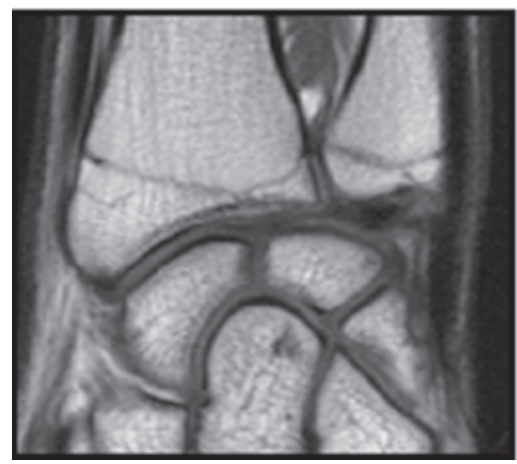

Grade II

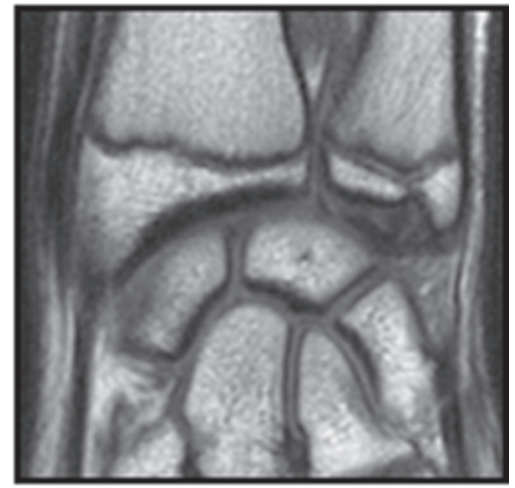

Grade IV

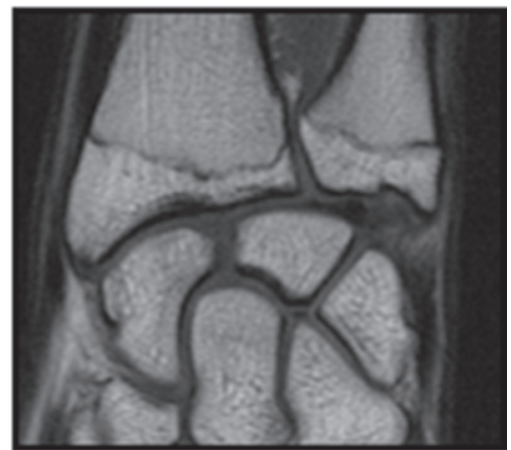

Grade VI

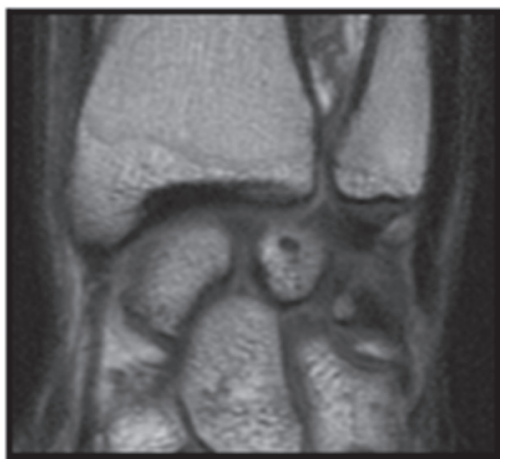

Figure 1 Images showing the grade of bone fusion as seen by magnetic resonance imaging of the distal radius epiphysis.

to stages of SM: maturity stage A or immature (fusion grade I), maturity stage B or developing (fusion grades II-IV), and maturity stage $\mathrm{C}$ or mature (fusion grades $\mathrm{V}$ and $\mathrm{VI}$ ) (Table 1 ).

Ten percent $(10 \%)$ of the images were randomly selected and re-evaluated by one of the readers to evaluate the intraobserver agreement by test-retest.

\section{Statistical analysis}

The Shapiro-Wilk tests were used to assess whether the different quantitative variables in the entire sample and in various subgroups came from a normally distributed population. To describe the clinical, anthropometric, and sexual maturity characteristics of the entire sample as well as the grade of bone fusion, frequency and percent measurements were used for qualitative variables, and measures of central tendency and dispersion were used for quantitative variables. If the quantitative variable came from a normally distributed population, the average and standard deviation were used; if it came from a population that was not normally distributed, the median and interquartile range were used.

The relationship of CA and sexual maturity with SM was established from the Kendall correlation coefficient. To assess differences in CA according to grade of bone fusion, nonparametric Analysis of Variance (ANOVA) was used (Kruskal-Wallis test).

The kappa index was used to perform analysis of interobserver and intra-observer agreement.

Data from each player were entered into a Microsoft Excel 2007 database. The information contained in all formats was reviewed to verify its completion. For all analyses, a statistical significance level of $\alpha=0.05$ was used, and EPIDAT 4.0 from the Pan-American Health Organisation and the software IBM SPSS Statistics version 21.0 were used. 


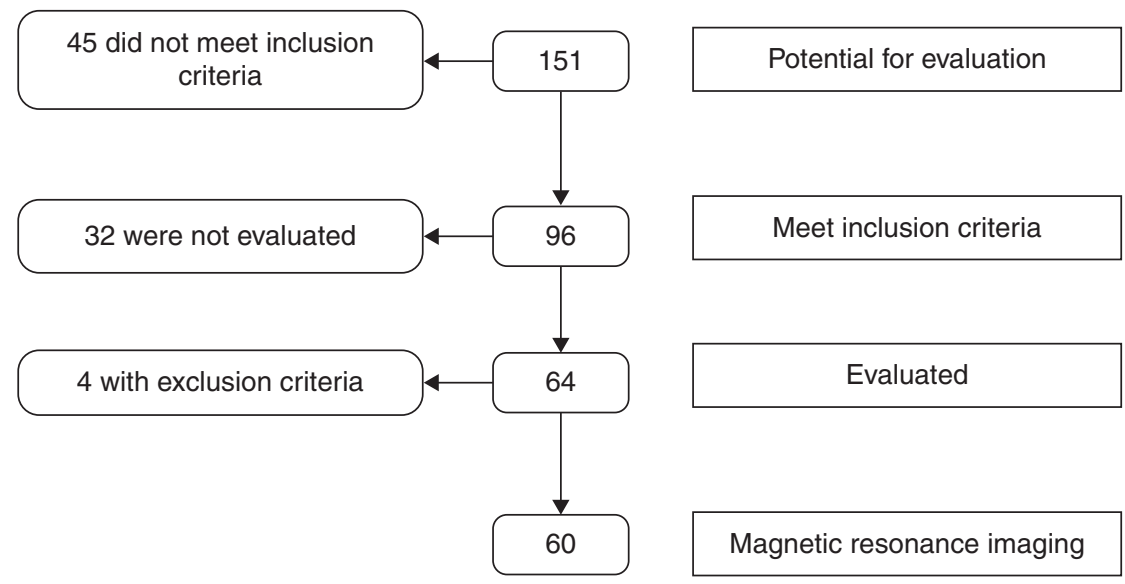

Figure 2 Flowchart showing the selection of study participants.

\section{Results}

From a total of 151 players who belonged to the selected clubs, 96 met the inclusion criteria. Sixty-four players attended the initial medical evaluation; for the others, telephone contact was not possible: they were found outside of the city or the country at the time of the call as they belonged to professional clubs, or they did not comply the scheduled appointment. Of the 64 players evaluated, four were excluded for medical reasons (three for a history of left distal radius fracture and one for asthma). Finally, MRI of the LDRE was performed on 60 players (Fig. 2).

Among the 60 football players included in the study, the mean age, body mass index, and percent body fat were $14.9 \pm 1.6$ years, $19.6 \pm 2.0 \mathrm{~kg} / \mathrm{m}^{2}$, and $11.1 \pm 1.2 \%$, respectively. Among the participants, the average sporting life was $4.3 \pm 2.5$ years, and the weekly training volume was $12.0 \pm 1.0 \mathrm{~h}$. A total of $89.8 \%$ of the players were attending high school, and $79.7 \%$ belonged to socioeconomic strata 1 , 2, or 3 . Three goalkeepers, 11 sides, 7 centres, 26 wingers, and 13 forwards were included (Table 2).

After evaluating the grade of maturity, considering secondary sexual characteristics, no players with signs of precocious or delayed puberty were found. According to Tanner, $1.8 \%, 14.5 \%, 27.3 \%, 23.6 \%$, and $32.7 \%$ of the athletes were in stages I, II, III, IV and V, respectively. According to classification of the grade of fusion of LDRE by MRI, $31.7 \%$, $60.0 \%$, and $8.3 \%$ of athletes were classified in stage $A, B$, and $\mathrm{C}$, respectively.

A correlation of CA and the Tanner stage of genital maturity with SM by MRI of the LDRE (Kendall's Tau_b 0.686 and 0.693 , respectively; $P<0.001$ ) was found (Table 3 ).

Differences were observed in the median of age between grades of fusion of LDRE by MRI in six- and three-categories classifications $(P<0.001)$ (Fig. 3).

In Fig. 4, the distribution of the grade of fusion of the LDRE by MRI in the six- and three-category classifications according to age and Tanner stage is shown. All players classified as stage $C$ were 17 or older and Tanner stage V. Only $27.8 \%$ of the football players in Tanner stage $V$ of the genitals were in stage $C$.

In the assessment of inter-observer agreement of the grade of epiphyseal fusion of the LDRE determined by MRI,
Table 2 Characteristics of adolescent soccer players included in the study.

\begin{tabular}{ll}
\hline Variables & $\begin{array}{l}\text { Adolescent soccer } \\
\text { players }(n=60)\end{array}$ \\
\hline Age (years) & $14.9 \pm 1.6$ \\
Weight $(\mathrm{Kg})$ & $54.1 \pm 10.6$ \\
Height (m) & $1.6 \pm 0.1$ \\
Body mass index (Kg. ${ }^{2}$ ) & $19.6 \pm 2.0$ \\
Body fat (percentage) & $11.1 \pm 1.2$ \\
Education (\%) & \\
$\quad$ High school & $89.8 \%$ \\
$\quad$ University & $5.0 \%$ \\
Tanner (\%) & \\
I & $1.8 \%$ \\
II & $14.5 \%$ \\
III & $27.3 \%$ \\
IV & $23.6 \%$ \\
$\quad$ V & $32.7 \%$ \\
Playing position (\%) & \\
$\quad$ Goalkeepers & \\
Sides & $5.0 \%$ \\
Centres & $18.3 \%$ \\
Wingers & $11.7 \%$ \\
Forwards & $43.3 \%$ \\
Weekly training volume (hours) & $12.0 \pm 1.0$ \\
Average sporting life (years) & $4.3 \pm 2.5$ \\
\hline Data are presented as mean 50 & $21.7 \%$ \\
\hline
\end{tabular}

Data are presented as mean \pm SD when appropriate.

a kappa index of $0.23(95 \% \mathrm{Cl}$ between $0.10-0.28 ; P<0.001)$ and $0.36(95 \% \mathrm{Cl}$ between $0.19-0.52 ; P<0.001)$ was found for six and three categories, respectively. In the assessment of intra-observer agreement, a kappa index of 0.79 (95\% Cl 0.62-0.96; $P<0.001)$ and 0.60 (95\% Cl 0.21-0.99; $P<0.001$ ) was found for the classification using six and three categories, respectively. No differences were found between kappa indices when comparing inter-observer and intra-observer agreement between the two classifications $(P>0.05)$. 
Table 3 Correlation between chronological age and the Tanner stage of genital maturity and skeletal maturity by nuclear magnetic resonance of the distal radius epiphysis in adolescent soccer players.

\begin{tabular}{|c|c|c|c|c|}
\hline Variables $(n=60)$ & & Age (years) & Tanner genital & Grade of bone maturation \\
\hline $\begin{array}{l}\text { Age } \\
\text { (years) }\end{array}$ & $\begin{array}{l}\text { Kendall's Tau_b } \\
P \text { value }\end{array}$ & 1.00 & $\begin{array}{r}0.727 \\
<0.001\end{array}$ & $\begin{array}{r}0.686 \\
<0.001\end{array}$ \\
\hline Tanner genital & $\begin{array}{l}\text { Kendall's Tau_b } \\
P \text { value }\end{array}$ & $\begin{array}{r}0.727 \\
<0.001\end{array}$ & 1.00 & $\begin{array}{r}0.693 \\
<0.001\end{array}$ \\
\hline $\begin{array}{l}\text { Grade of bone } \\
\text { maturation }\end{array}$ & $\begin{array}{l}\text { Kendall's Tau_b } \\
P \text { value }\end{array}$ & $\begin{array}{r}0.686 \\
<0.001\end{array}$ & $\begin{array}{r}0.693 \\
<0.001\end{array}$ & 1.00 \\
\hline
\end{tabular}

\section{Discussion}

In our study, we found a relationship between CA, sexual maturity by Tanner stage of the genitals, and SM by MRI of the LDRE in adolescent football players in Medellin, Colombia. According to CA, grades of fusion had higher discriminatory ability in children less than 13 years old, where $100 \%$ showed stage A. Additionally, all individuals classified in stage $C$ were 17 or older and Tanner stage V. These results have implications for competitions, particularly in the sub17 category, where the greatest difficulties arise. In this sense, the possibility is raised of restricting participation in global tournaments of that category only to individuals with stage $A$ or $B$ of $S M$.

The grouping into 3 categories, i.e., stage A, B, or C, for LDRE grade of fusion determined by MRI, allows a more practical approach to SM and avoids the confusion that can occur with a larger number of categories.

Despite the positive correlations between CA, sexual maturity by Tanner stage of genitals (biological maturity), and grade of bone fusion by MRI of the LDRE, an asynchronous relationship of biological maturity (BM) to bone fusion was observed. While $32.7 \%$ of individuals were Tanner stage $\mathrm{V}$, only $8.3 \%$ presented stage $\mathrm{C}$ bone fusion. These findings corroborate the results described in other studies that have reported a temporal difference in the development of the hypothalamic-pituitary-gonad axis and SM. ${ }^{7,8}$

BM is a topic of interest and controversy in different health areas, such as paediatric endocrinology, ${ }^{12}$ forensic sciences, ${ }^{13,14}$ and sports medicine. ${ }^{15}$ In sports medicine, it is an important issue because the development of physical and coordinative abilities is related to the grade of BM. ${ }^{16-18}$ In sports, the desire to win and inherent financial rewards have led to misconduct through falsifying or supplanting the legal documentation of sports players, primarily in football. ${ }^{1}$

Various researchers have related aspects of BM, such as the development of secondary sexual characteristics (pubic and underarm hair, breasts, genitals), SM, and CA. ${ }^{7}$ Despite the natural variability at age of onset of puberty, we found a high correlation between Tanner stage and CA, which could be explained by sexual and ethnic characteristics of our population. Also, although BM and SM are correlated, they are asynchronous in the healthy adolescent. One study demonstrated that BM occurs 2-3 years before SM. ${ }^{7}$

The evaluation of $S M$ has been a research topic for many years and has been correlated with CA in children and adolescents. ${ }^{19}$ However, traditional methods for the evaluation of skeletal age can underestimate or overestimate CA by up to 5 years. ${ }^{19}$ These techniques are based on common sequential maturation of the carpal bones during
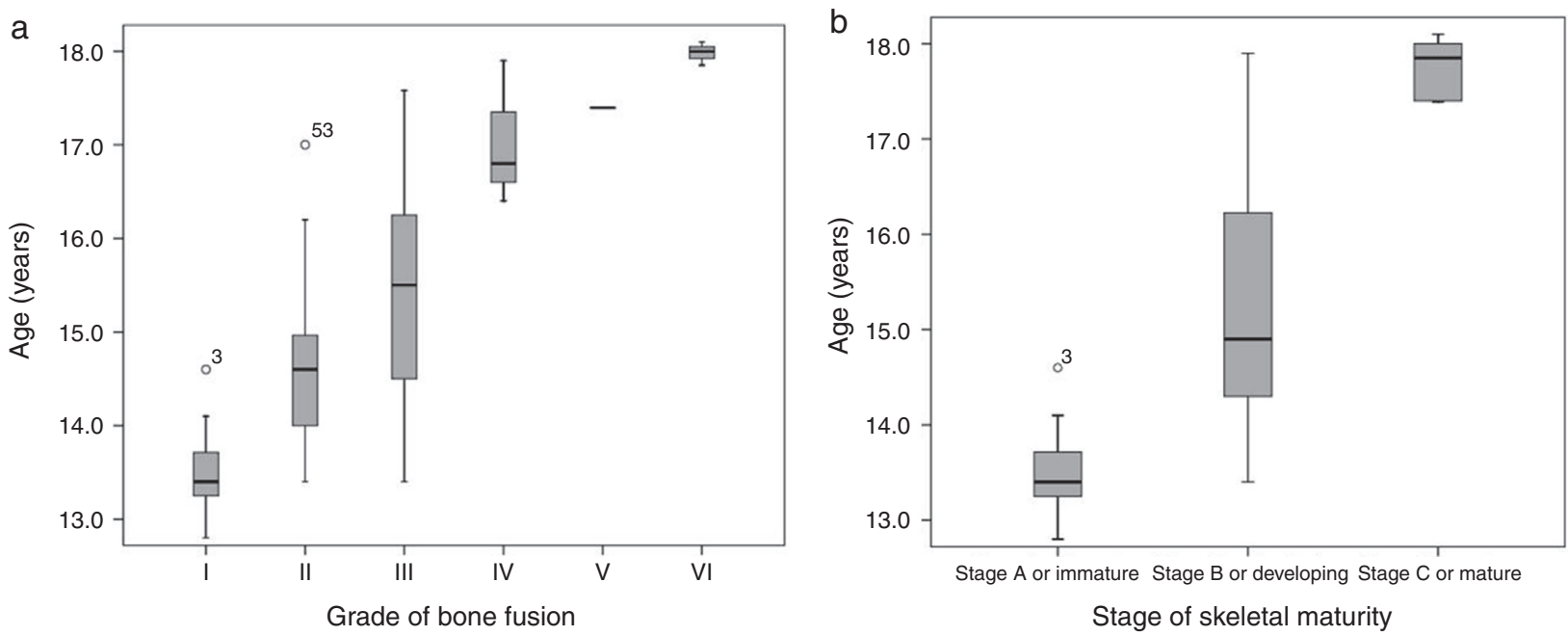

Figure 3 Box plots of age according to the grades of fusion of the distal radius epiphysis by nuclear magnetic resonance in the rankings of six (a) and three (b) categories. 
a

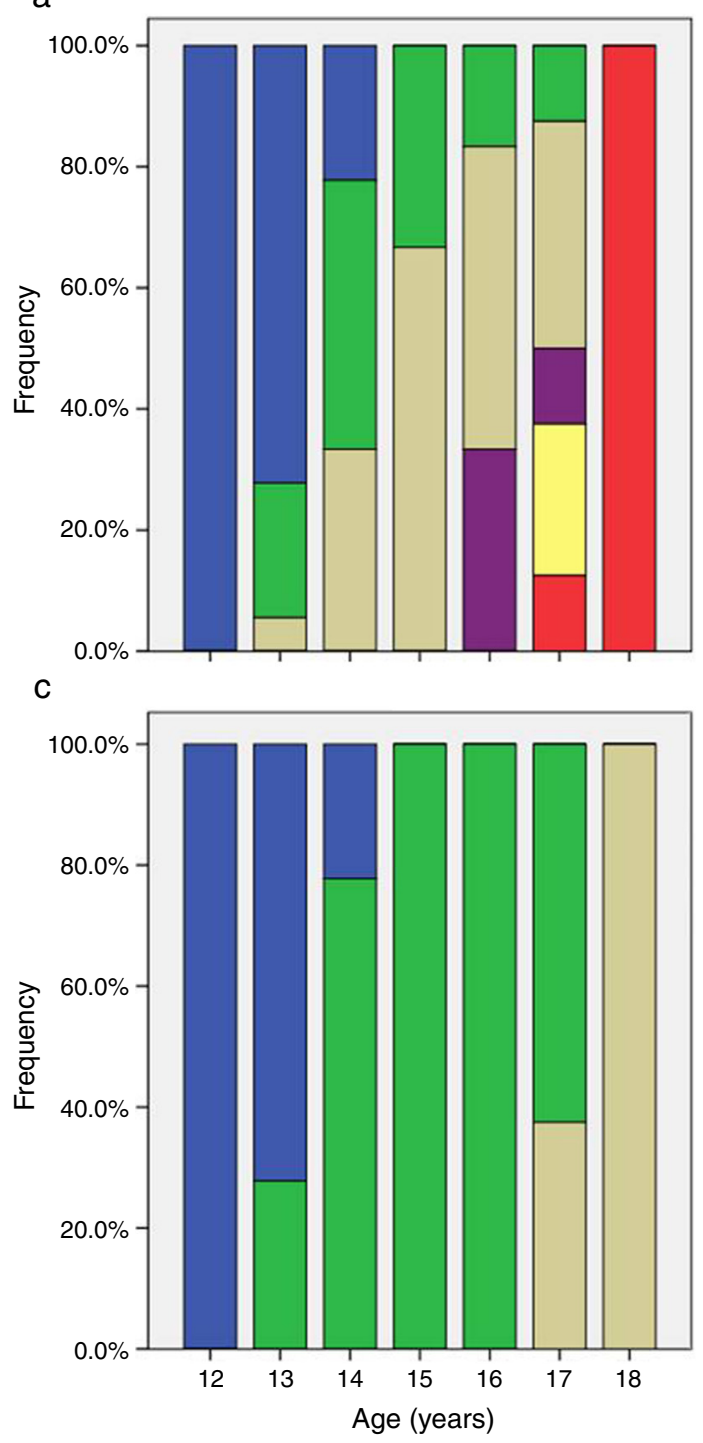

b

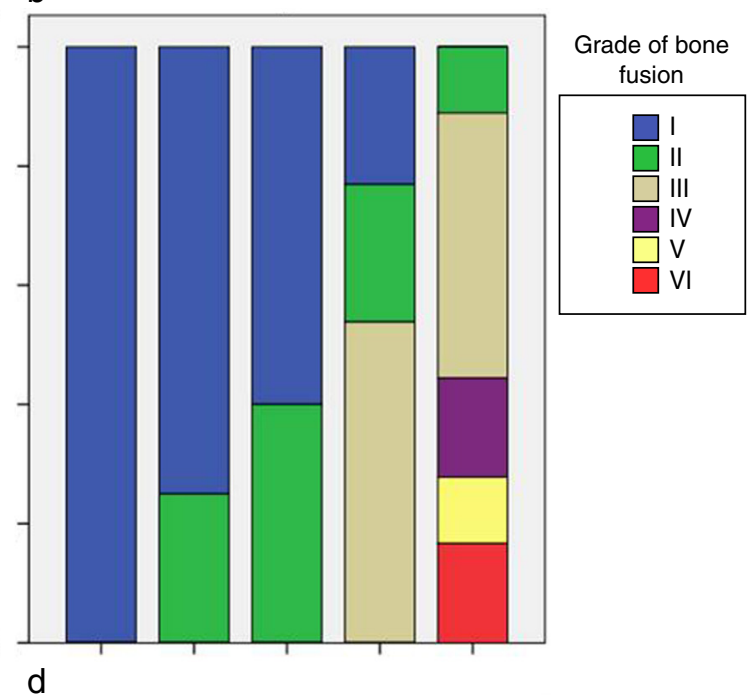

d

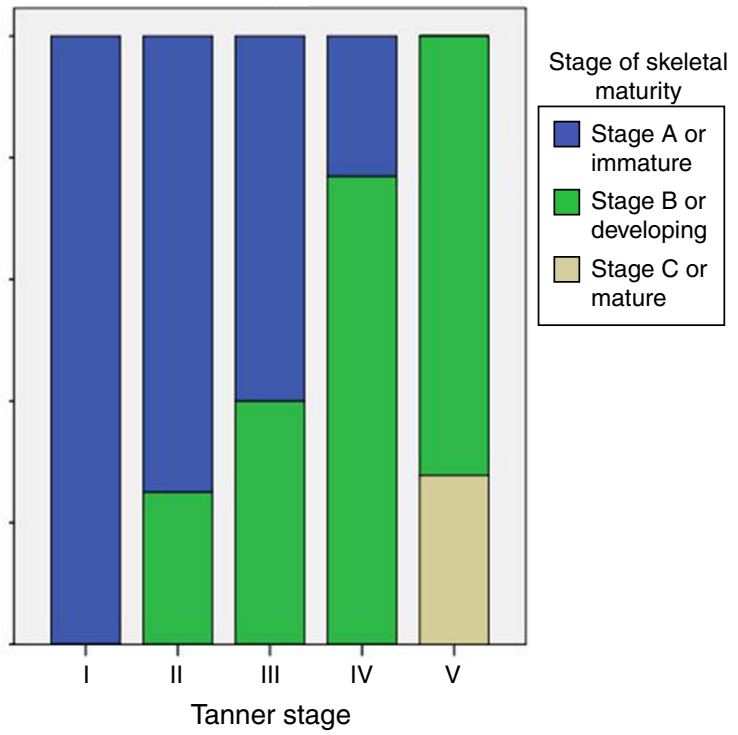

Figure 4 Distribution of the grade of fusion of the distal radius epiphysis by nuclear magnetic resonance in the rankings of six (a and $b$ ) and three ( $c$ and d) categories according to age and Tanner.

stages of biological development. Studies have shown that between 15 and 17 years of age, the carpus, metacarpals, and phalanges are completely developed. For this reason, evaluation of SM at older ages is based on the grade of epiphyseal fusion of the radius and ulna because they are the last bones to fuse. ${ }^{20}$

The most commonly used methods for assessing bone age are Fels and TW3, which use X-ray imaging to determine growth of the carpal bones and wrist. The Fels method was developed in the Fels Longitudinal Study and included middle-class people from Ohio in the United States. In the Fels method, epiphyseal fusion of the distal radius is classified into 4 grades for the medial and lateral third and 3 grades for the central third. The Fels protocol assigns categories to specific indicators of maturity and uses ratings of the linear measurements of the width of the epiphysis and metaphysis of long bones. The scores are entered into software (Felshw 1.0) that calculates bone age and the standard error associated with the estimate. ${ }^{21}$
The TW3 method was developed in youth in Europe (Great Britain, Belgium, Italy, and Spain), South America (Argentina), the United States (Texas), and Japan. ${ }^{22}$ This technique differs from its predecessor, TW2, which was conducted primarily on the British population in $1950 .{ }^{23}$ For TW3, bones in the left hand and wrist are compared with figures and descriptions of the reference population; it is limited to the radius, ulna, and short bones of the first, third, and fifth phalanx.

Although both methods (Fels and TW3) have been widely used throughout the world, they have limitations due to the estimation of greater bone age than chronological age in young football players. ${ }^{8,24}$ In addition, they are susceptible to inter- and intra-observer variability related to demographic, nutritional, and health aspects, and there may be genetic differences between the reference population and the individuals to whom the methods are applied. ${ }^{25}$

Different studies conducted by FIFA have shown that the grade of fusion of the LDRE by MRI is correlated with 
chronological age in adolescent football players. ${ }^{5,6}$ Importantly, MRI does not have the risks associated with radiation in minors. Additionally, planar radiographs of the distal radial epiphysis overestimate fusion in the age ranges between 15 and 19 years compared with MRI. ${ }^{26}$

Studies that evaluate the grade of fusion of the LDRE by $M R I$ do not define a particular bone age but rather grades of SM that are related to CA. This method avoids the limitations of having a bone age that may be higher or lower than CA. In addition, it could have practical applications for establishing competition categories according to grade of SM.5,6 Classification of the grade of SM in 3 categories could predict with certainty that everyone in stage $C$ is mature and is at least 17 or older.

This research work has certain limitations, such as including a convenience sample and voluntary participation of the subjects, which can generate a selection bias. However, although all individuals in the sampling frame were invited to participate, not meeting inclusion criteria limited the number of players finally assessed. The assessed population is from Antioquia and is not representative of the different areas of Colombia, which vary demographically and nutritionally. Non-impersonation of documentation is difficult to prove, as the documents can be legal; however, our results are similar to the results reported in the "standard population" of FIFA, ${ }^{6}$ and the rigour of the established protocol for verifying documentation supports the information quality.

Our results agree with suggestions made in other studies, where the categorisation of competition is proposed according the grade of maturity and not exclusively CA. ${ }^{11}$ In two subjects of the same age, it is possible to find one individual at SM stage B and the other at stage C. Regardless of age, individuals classified as mature should participate in the upper categories. Considering the classification of the grade of SM would allow a cleaner, more homogenous game and would ensure that immature or developing subjects compete with their real counterparts.

\section{Conclusion}

A relationship of CA and sexual maturity with SM by MRI of the LDRE in adolescent football players was found. Differences were observed in the median of age between grades of fusion of LDRE by MRI. All players classified as stage C were 17 or older and Tanner stage V. Classifying the grade of SM by stages A, B, or C (immature, developing, or mature), according to the fusion of the LDRE could be more practical and could have implications for competition.

\section{Funding}

This study was conducted with resources from CEDIMED, the Medellin Independent Sports Corporation, the Football League of Antioquia, and the Graduate School in Applied Medicine to Physical Activity and Sport of the University of Antioquia.

\section{Conflict of interest}

The authors declare no conflicts of interest.

\section{Authors' contributions}

Study conception and design: JBS, OSZ, JOC, JGV; Acquisition of data: JBS, OSZ, GDD; Statistical analysis: JBS, JGV; Analysis and interpretation of data, drafting of the manuscript and critical revision of the manuscript for important intellectual content: JBS, OSZ, JOC, GDD, JGV.

\section{Acknowledgements}

Our sincere thanks to CEDIMED, the Medellin Independent Sport Corporation, the Football League of Antioquia, and the Graduate School in Applied Medicine to Physical Activity and Sport of the University of Antioquia.

We also want to thank Dr. Juan C. Calderón from University of Antioquia for his critical review of the manuscript and his support for its publication.

\section{References}

1. Dvorak J. Detecting over-age players using wrist MRI: science partnering with sport to ensure fair play. $\mathrm{Br} \mathrm{J}$ Sports Med. 2009;43:884-5.

2. Malina RM, Pena Reyes ME, Eisenmann JC, Horta L, Rodrigues J, Miller R. Height, mass and skeletal maturity of elite Portuguese soccer players aged 11-16 years. J Sports Sci. 2000;18:685-93.

3. Oestreich AE. Tanner-Whitehouse versus Greulich-Pyle in bone age determinations. J Pediatr. 1997;131 1 Pt 1:5-6.

4. Gonzalez AJ. Radiation safety standards and their application: international policies and current issues. Health Phys. 2004;87:258-72.

5. Dvorak J, George J, Junge A, Hodler J. Age determination by magnetic resonance imaging of the wrist in adolescent male football players. Br J Sports Med. 2007;41:45-52.

6. Dvorak J, George J, Junge A, Hodler J. Application of MRI of the wrist for age determination in international U-17 soccer competitions. Br J Sports Med. 2007;41:497-500.

7. Flor-Cisneros A, Roemmich JN, Rogol AD, Baron J. Bone age and onset of puberty in normal boys. Mol Cell Endocrinol. 2006;254-255:202-6.

8. Malina RM, Coelho ESMJ, Figueiredo AJ, Carling C, Beunen GP. Interrelationships among invasive and non-invasive indicators of biological maturation in adolescent male soccer players. J Sports Sci. 2012;30:1705-17.

9. Faulkner J. Physiology of swimming and diving. In: Falls $\mathrm{H}$, editor. Exercise physiology. Baltimore: Academic Press; 1968. p. 415-45.

10. Tanner JM. Growth at adolescence. With a general consideration of the effects of hereditary and environmental factors upon growth and maturation from birth to maturity. 2nd ed. London: Oxford, Blackwell Scientific Publications; 1962.

11. Malina RM, Cumming SP, Morano PJ, Barron M, Miller SJ. Maturity status of youth football players: a noninvasive estimate. Med Sci Sports Exerc. 2005;37:1044-52.

12. Spadoni GL, Cianfarani S. Bone age assessment in the workup of children with endocrine disorders. Horm Res Paediatr. 2010;73:2-5.

13. Stein KM, Grunberg K. Forensic radiology. Radiologe. 2009;49:73-84, quiz 85.

14. Franklin D. Forensic age estimation in human skeletal remains: current concepts and future directions. Leg Med (Tokyo). 2010;12:1-7.

15. Moore SA, Moore M, Klentrou P, Sullivan P, Falk B. Maturity status in male child and adolescent athletes. J Sports Med Phys Fitness. 2010;50:486-93. 
16. Malina RM, Eisenmann JC, Cumming SP, Ribeiro B, Aroso J. Maturity-associated variation in the growth and functional capacities of youth football (soccer) players 13-15 years. Eur J Appl Physiol. 2004;91(5-6):555-62.

17. Vandendriessche JB, Vaeyens R, Vandorpe B, Lenoir M, Lefevre J, Philippaerts RM. Biological maturation, morphology, fitness, and motor coordination as part of a selection strategy in the search for international youth soccer players (age 15-16 years). J Sports Sci. 2012;30:1695-703.

18. Soarez H, Fragoso I, Massuça L, Barrigas C. Impacto de la maduración y de los puestos específicos en la condición física en jóvenes futbolistas. Apunts Med Esport. 2012;47:73-81.

19. Malina RM, Pena Reyes ME, Figueiredo AJ, Coelho E, Silva MJ, Horta L, et al. Skeletal age in youth soccer players: implication for age verification. Clin J Sport Med. 2010;20:469-74.

20. Gilsanz V, Ratib O. Hand bone age: a digital atlas of skeletal maturity. Berlin: Springer; 2005.

21. Roche AF, Chumlea W, Thissen D. Assessing the skeletal maturity of the hand-wrist: Fels method. Springfield, IL: Charles C. Thomas; 1988.
22. Tanner JM, Healy MJR, Goldstein H, Cameron N. Assessment of skeletal maturity and prediction of adult height (TW3 method). 3rd ed. London: WB Saunders; 2001.

23. Tanner JM, Whitehouse RH, Cameron N, Marshall WA, Healy MJR, Goldstein $\mathrm{H}$. Assessment of skeletal maturity and prediction of adult height (TW2 method). 2nd ed. New York: Academic Press; 1981.

24. Malina RM, Chamorro M, Serratosa L, Morate F. TW3 and Fels skeletal ages in elite youth soccer players. Ann Hum Biol. 2007;34:265-72.

25. van Lenthe FJ, Kemper HC, van Mechelen W. Skeletal maturation in adolescence: a comparison between the Tanner-Whitehouse II and the Fels method. Eur J Pediatr. 1998;157:798-801

26. George J, Nagendran J, Azmi K. Comparison study of growth plate fusion using MRI versus plain radiographs as used in age determination for exclusion of overaged football players. $\mathrm{Br} \mathrm{J}$ Sports Med. 2012;46:273-8. 